\title{
Sildenafil citrate adjuvant treatment in women with polycystic ovary syndrome following clomiphene failure: A randomized controlled trial \\ Original
}

Article

Sherif Ashoush and Ahmed Abdelshafy

Department of Obstetrics and Gynecology, Faculty of Medicine, Ain Shams University.

\begin{abstract}
Objective: The widespread classic PCOS treatment algorithm, consisting of 6-12 cycles of clomiphene followed by shifting to gonadotropins in case of failure to conceive, doesn't really address the cause of failure to conceive despite documented ovulation. Sildenafil citrate improves uterine blood flow, enhances endometrial development and modulates endometrial receptivity. Hence, this study monitored the ovarian response, endometrial development and subendometrial Doppler changes in PCOS women with previous clomiphene citrate failure following the use of adjuvant sildenafil citrate instead of shifting to gonadotropins.

Patients and Methods: A double-blinded randomized controlled trial was conducted in Ain-Shams University Women's Hospital on 850 PCOS women with clomiphene failure. Those were randomized to clomiphene therapy, either with adjuvant placebo or sildenafil citrate ( $25 \mathrm{mg}$ orally 6 hourly), starting from the 6 th day till the end of the cycle.

Folliculometry, every other day, started on the 10th day of the cycle. When $\geq 1$ follicle reached a size $\geq 18 \mathrm{~mm}$, transvaginal ultrasound assessment of the endometrium and uterine/subendometrial Doppler was done. The resulting pregnancy rates were recorded.

Results: The sildenafil group developed higher endometrial thickness $(10.6 \pm 1.3$ versus $9.4 \pm 1.5$; $\mathrm{p}<0.001)$, a higher percentage of women with trilaminar endometrium $(78.35 \%$ versus $59.76 \% ; \mathrm{p}<0.001)$ was found while the lower percentage was found with subendometrial and uterine artery Doppler indices $(\mathrm{p}<0.001$ for all). It also developed higher pregnancy rates $(43.7 \%$ versus $34.5 \%, \mathrm{p}=0.006$; $\mathrm{NNT}=10.8,95 \% \mathrm{CI}: 6.36-37.84)$.

Conclusion: Sildenafil adjuvant therapy significantly increased pregnancy rates, improved endometrial development in terms of endometrial thickness and pattern as well as uterine and subendometrial blood flow.
\end{abstract}

Key Words: Sildenafil citrate, clomiphene failure, polycystic ovary syndome, endometrial receptivity, subendometrial doppler.

Received: 17 July 2019, Accepted: 28 July 2019

Corresponding Author: Sherif Ashoush, MD, Department of Obstetrics and Gynecology, Faculty of Medicine, Ain Shams University, Cairo, Egypt, Tel.: +201222660266, E-mail: sherifashoush@med.asu.edu.eg

ISSN: 2090-7265, August 2019, Vol. 9, No. 3

\section{INTRODUCTION}

To-date, no consensus exists regarding the optimum management of women with polycystic ovary syndrome (PCOS) who ovulate with clomiphene citrate treatment, but fail to conceive, i.e. clomiphene failure. Most published trials focused on either therapy, naive PCOS women or those who remained anovulatory despite maximum, dose induction of ovulation with clomiphene citrate, i.e. clomiphene-resistant ${ }^{[1]}$. Despite being a larger population compared to clomiphene-resistant women, clinical trials didn't address the optimum management of women with clomiphene failure nor investigated the potential causes of such failure ${ }^{[1]}$. Moreover, guidelines are not consistent in this regard; whereas NICE guideline suggests limiting the number of ovulatory cycles with clomiphene citrate treatment with failure of conception to a maximum of six cycles ${ }^{[2]}$. The Thessaloniki ESHRE/ ASRM PCOS Consensus Workshop Group held the same recommendation, but considered extending clomiphene citrate induction to a maximum of 12 cycles on an individual basis ${ }^{[3]}$. Both guidelines recommend the next step in the management of these patients to switch directly to gonadotropin induction of ovulation ${ }^{[2-3]}$. In practice, however, large variation exists among clinicians in dealing with these patients; whereas some clinicians start gonadotrophin induction directly, some opt to extend clomiphene citrate induction with or without intrauterine insemination ${ }^{[1]}$.

In comparison, $50 \%$ cumulative livebirth rate was estimated after second-line induction of ovulation with gonadotropins ${ }^{[4]}$; whereas $54 \%$ cumulative ongoing pregnancy rate was reported by Weiss et al. with extended 
induction of ovulation with clomiphene citrate for up to 12 cycles $^{[1]}$. This comparable outcome together with the difference in cost, the need for close ultrasonographic follow up and the increased incidence of multiple pregnancy and ovarian hyperstimulation syndrome associated with gonadotrophin induction of ovulation ${ }^{[4]}$ might favor the use of extended clomiphene induction of ovulation.

In addition to the comparable pregnancy outcome, it seems that the widespread classic PCOS treatment algorithm of clomiphene/gonadotropins/IVF doesn't address the cause of failure to conceive, despite the ovulatory cycles, in any of its steps, nor addresses a specific management for each cause of failure. It is evident that failure of conception might be drug-related, e.g. antiestrogenic effect of clomiphene citrate ${ }^{[5]}$ or might be due to another defect that might also cause failure of other treatment option(s). It is not uncommon that a woman recapitulates the whole algorithm to the stage of repeated IVF/ICSI before questioning defects of endometrial receptivity, for instance, to realize that failure of conception was due to a missed diagnosis of an endometrial defect rather than clomiphene or gonadotrophin failure.

Sildenafil citrate is a phosphodiesterase-5 inhibitor that enhances subendometrial blood flow by potentiating the vasodilatory effect of nitric oxide ${ }^{[6]}$. It was reported to improve uterine blood flow, enhance endometrial development ${ }^{[7-10]}$ and modulate endometrial receptivity ${ }^{[1]}$. Thus, it was used with varying success in the setting of repeated IVF failure with poor endometrial development ${ }^{[8]}$ and to lesser extent in the setting of clomiphene citrateinduced thin endometrium ${ }^{[12,13]}$.

This study aimed to monitor the ovarian response in PCOS women with previous clomiphene citrate failure following the use of adjuvant sildenafil citrate, as a prior step to shifting to gonadotropin therapy. It also investigated their transvaginal subendometrial Doppler changes and their endometrial development.

\section{PATIENTS AND METHODS}

The current study was a single-center, prospective, double-blind, randomized placebo-controlled trial (RCT) and registered with the U.S. FDA clinicaltrials.gov, NCT02663830. The study plan was approved by the research committee in the Department of Obstetrics and Gynecology, Ain-Shams University. It was conducted in the infertility clinics of Ain-Shams Women's University, Cairo, Egypt, in the period between April 2016 and May 2018.

\section{Participants}

A total of 850 eligible PCOS women, aged 21-35 years, with clomiphene failure were enrolled in this study and randomized to extended clomiphene therapy, either with adjuvant sildenafil citrate or placebo. Diagnosis of PCOS was based upon the revised 2003 consensus on diagnostic criteria of polycystic ovary syndrome by the Rotterdam ESHRE/ASRM-Sponsored PCOS Consensus Workshop Group $^{[14]}$. Clomiphene failure was defined as failure of conception despite six ovulatory cycles on clomiphene citrate treatment with a maximum daily dosage of $150 \mathrm{mg}$ for 5 days in each cycle ${ }^{[15]}$. Women with $\mathrm{BMI}>30 \mathrm{Kg} /$ $\mathrm{m} 2$, diabetes mellitus, chronic medical disorders, other concomitant cause of infertility (e.g. abnormal semen analysis, tubal abnormalities, endometriosis, etc) or pelvic pathology (e.g. endometrial polyp, hyperplasia, ovarian cyst, etc) were excluded from the study. Metformin treatment didn't exclude the patient from the study.

\section{Randomization}

After obtaining informed consent, patients were randomized to either the sildenafil or placebo group using a computer generated list concealed by means of sequentially numbered, otherwise identical sealed envelopes (SNOSE), each containing a $2 \times 2$ inch paper with a written code designating the assigned group. Double-blinding was ensured by using visually identical tablets for both the active drug and the placebo.

\section{Medical intervention}

Clomiphene citrate (Clomid $\AA$ 50mg, Hoechst Marion Russel, Cairo, Egypt) was started using the same daily ovulatory dose used in the previous cycles on the 2nd day of the menstrual cycle for 5 days for a maximum of six induction cycles. Starting the $6^{\text {th }}$ day of the cycle, patients received either $25 \mathrm{mg}$ of sildenafil citrate (Sildin ${ }^{\circledR} 25 \mathrm{mg}$, EIPICO pharma, Cairo, Egypt) orally every 6 hours till the end of the cycle in the sildenafil group or a visually identical placebo tablets with the same regimen in the placebo group.

\section{Ultrasonographic folliculometric and Doppler assessment of ovulation induction cycle}

Folliculometric assessment of patients was done using Voluson E6 (General Electric Healthcare ${ }^{\circledR}$, Waukesha, WI, USA) ultrasound machine with a $6.5 \mathrm{MHz}$ endovaginal probe every other day starting the 10th day of the induction cycle. When at least one follicle reached a size $\geq 18 \mathrm{~mm}$, assessment of endometrial thickness, pattern, uterine artery and subendometrial blood flow was done followed by triggering of ovulation by $10,000 \mathrm{IU}$ of human chorionic gonadotropin (Choriomon ${ }^{\circledR}$, IBSA, Switzerland or Profasi ${ }^{\circledR}$, Serono, Egypt) intramuscularly with timed intercourse 24-36 hours thereafter.

Ultrasonographic endometrial assessment was done by obtaining longitudinal view of the uterus, measuring endometrial stripe thickness and describing it by one of the following patterns: trilaminar (triple line pattern consisting 
of two hypoechoic layers with a central hyperechoic line inbetween), intermediate isoechoic (having same reflectivity and pattern) or homogenously hyperechogenic. Then after activating color Doppler mode, choosing pulse repetition frequency for color velocity range of $3 \mathrm{~cm} / \mathrm{sec}$ and adjusting color gain to $80 \pm 2 \%$, pulsatile color signals in the subendometrial region were localized; for which resistivity index (RI) and pulsatility index (PI) were calculated after obtaining at least three continuous Doppler waveforms while keeping insonation angle at $0^{\circ} \mathrm{C}$. Simultaneously, uterine arteries were sampled bilaterally lateral to the cervix near the internal os and pulsatility index (PI) on either sides was calculated.

\section{Monitoring for side effects}

The patients were followed up to detect side effects due to clomiphene including nausea, abdominal pain, headache, blurred vision, vaginal dryness or multiple pregnancies. They were also monitored for side effects due to sildenafil use including headache, blurring of vision, hypotension, tachycardia, flushing, abdominal pain, nausea or dyspepsia. Each side effect was assessed using objective scaling scoring system: 0 (no symptoms), 1 (mild not requiring any change in life style), 2 (severe, controlled with another method), 3 (severe, not controlled but the patient is still accepting to continue using it) and 4 (severe, not controlled and the patient is not accepting to continue using the treatment).

\section{Follow up of induction cycle outcomes}

$\beta$-hCG level was measured two weeks after triggering of ovulation and levels $>10 \mathrm{mIU} / \mathrm{mL}$ were used to confirm pregnancy. Clinical pregnancy was defined by ultrasonographic visualization of intrauterine fetal cardiac pulsations 2 weeks later.

\section{Statistical analysis}

Data were analyzed using SPSS version 24.0 (SPSS Inc, Chicago, IL, USA). Data were analyzed on intention to treat basis. Parametric numerical data were presented as mean \pm standard deviation; whereas non-parametric numerical data were presented as median with interquartile range. Categorical data were presented as number and percentage. Two-group comparisons for numerical data were done using the Student $t$ test for parametric data and using the Mann-Whitney test for non-parametric data. Categorical data were compared using Chi-square test or Fisher exact test. Significance level was set at $\mathrm{p} \leq 0.05$.

\section{Sample size justification}

According to the results of Weiss et al ${ }^{[1]}$, pregnancy rate in PCOS patients with extended clomiphene therapy for another six cycles following failure to conceive in the first six cycles was estimated to be $37.7 \%$. Sample size calculation using PASS $\AA 15$ (NCSS $\AA$, LCC, Utah, US), assuming an incremental effect size of adjuvant sildenafil treatment in clinical pregnancy rate of $10 \%$, required a minimum sample size of 806 patients randomized into two groups; that was inflated to 850 patients to compensate for an assumed $5 \%$ drop-out rate.

\section{RESULTS}

A total of 850 PCOS women with clomiphene failure were randomized to either sildenafil or placebo groups. We excluded 42 women due to withdrawal from completing the study to shift to gonadotrophin induction $(n=48)$, adjuvant IUI $(\mathrm{n}=54)$ or IVF/ICSI $(\mathrm{n}=26)$ or due to personal reasons $(\mathrm{n}=5)$, intolerance to sildenafil side effects $(\mathrm{n}=7)$ or attrition during follow up $(\mathrm{n}=22)$. However, they were all included in statistical analysis following the intention to treat principle. The process of recruitment and handling the study population during the course of the study is shown in the CONSORT flow diagram (Fig. 1).

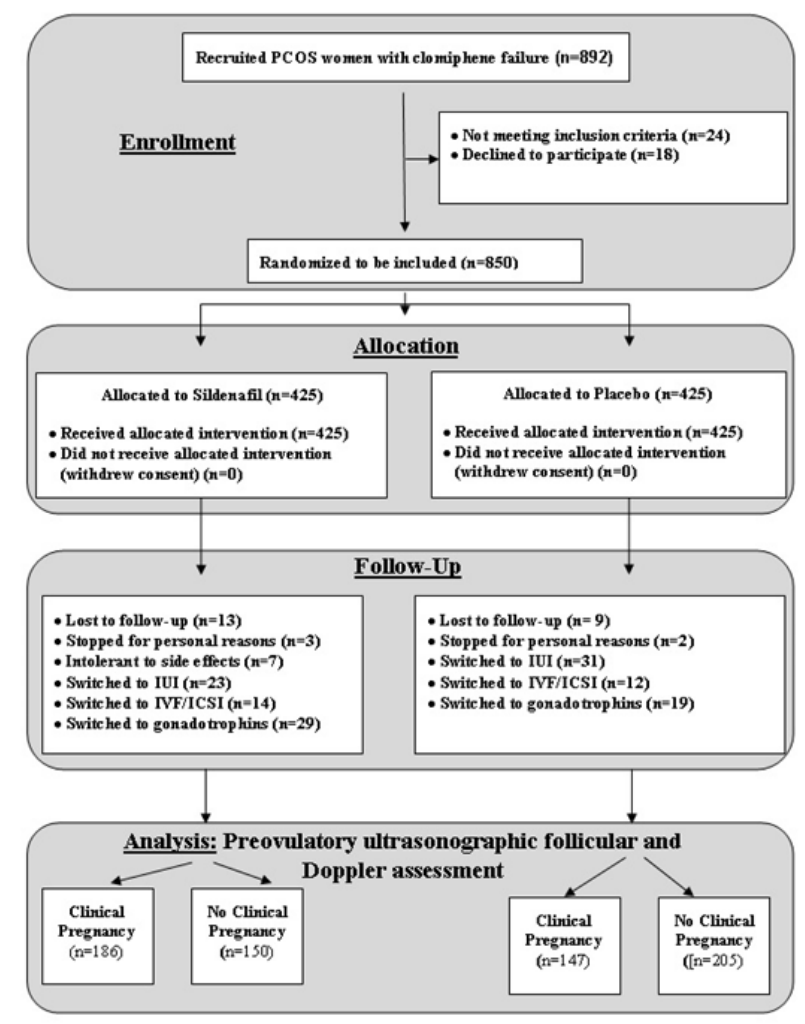

Fig. 1: CONSORT flow diagram showing the recruitment and handling of the study population during the course of the study.

No statistically significant differences were found between both groups regarding basal demographic, hormonal and clinical characteristics (Table 1); whereas preovulatory follicumetric measurements didn't differ significantly between both groups. Endometrial thickness and the proportion of women with trilaminar endometrial pattern were significantly higher in the sildenafil group compared to the placebo group reflecting enhanced endometrial development in the sildenafil group. Both subendometrial 
and uterine artery Doppler indices were significantly lower in the sildenafil group denoting increased uterine blood flow (Table 2). Clinical pregnancy rate was significantly higher in the sildenafil group $(43.7 \%$ vs $34.5 \%)$ with a calculated number needed to treat (NNT) of $10.8(95 \% \mathrm{CI}$ : 6.36-37.84) (Table 3,4).

Table 1: Basal demographic, clinical and hormonal characteristics in the two study groups.

\begin{tabular}{|c|c|c|c|}
\hline & Sildenafil Group & Placebo Group & p-value \\
\hline Age (years) & $26.1 \pm 3.4$ & $26.3 \pm 4.1$ & 0.43 \\
\hline BMI $\left(\mathrm{Kg} / \mathrm{m}^{2}\right)$ & $28.1 \pm 2.4$ & $28.3 \pm 1.8$ & 0.16 \\
\hline \multicolumn{4}{|l|}{ Type of infertility } \\
\hline Primary & $248(58.35 \%)$ & $265(62.35 \%)$ & 0.26 \\
\hline Secondary & $177(41.64 \%)$ & $160(37.64 \%)$ & \\
\hline \multicolumn{4}{|c|}{ Clinical features of PCOS } \\
\hline Irregular cycles & $255(60.0 \%)$ & $263(61.8 \%)$ & 0.62 \\
\hline Hirsutism & $239(56.2 \%)$ & $251(59.02 \%)$ & 0.44 \\
\hline PCO morphology & $331(77.8 \%)$ & $314(73.8 \%)$ & 0.19 \\
\hline \multicolumn{4}{|c|}{ Basal hormonal profile } \\
\hline FSH (mIU/mL) & $5.6 \pm 1.3$ & $5.4 \pm 1.9$ & 0.06 \\
\hline $\mathrm{LH}(\mathrm{mIU} / \mathrm{mL})$ & $10.6 \pm 1.9$ & $10.4 \pm 2.1$ & 0.13 \\
\hline $\mathrm{TSH}(\mu \mathrm{IU} / \mathrm{mL})$ & $2.2 \pm 0.9$ & $2.1 \pm 0.7$ & 0.06 \\
\hline $\begin{array}{l}\text { Free testosterone } \\
(\mathrm{ng} / \mathrm{dL})\end{array}$ & $3.8 \pm 1.4$ & $3.6 \pm 1.8$ & 0.06 \\
\hline Prolactin (ng/mL) & $16.3 \pm 3.0$ & $16.6 \pm 4.1$ & 0.22 \\
\hline $\begin{array}{l}\text { Ovulatory } \\
\text { clomiphene citrate } \\
\text { dose }(\mathrm{mg})\end{array}$ & $80.76 \pm 32.5$ & $84.61 \pm 31.5$ & 0.07 \\
\hline
\end{tabular}

Table 2: Preovulatory ultrasonographic folliculometric, endometrial and Doppler assessment of induction cycles in the two groups.

\begin{tabular}{lccc}
\hline & $\begin{array}{c}\text { Sildenafil } \\
\text { Group }\end{array}$ & $\begin{array}{c}\text { Placebo } \\
\text { Group }\end{array}$ & p-value \\
\hline Dominant follicle size & $20.1 \pm 3.2$ & $19.8 \pm 2.1$ & 0.10 \\
Endomterial thickness & $10.6 \pm 1.3$ & $9.4 \pm 1.5$ & $<0.001$ \\
Endometrial pattern & & & \\
Trilaminar & $333(78.35 \%)$ & $254(59.76 \%)$ & $<0.001$ \\
Isoechoic & $73(17.17 \%)$ & $110(25.88 \%)$ & \\
Hyperechogenic & $19(4.4 \%)$ & $61(14.35 \%)$ & \\
Subendometrial Doppler indices & & \\
Resistivity index (RI) & $0.73 \pm 0.13$ & $0.87 \pm 0.11$ & $<0.001$ \\
Pulsatility index (PI) & $1.08 \pm 0.33$ & $2.09 \pm 1.01$ & $<0.001$ \\
Uterine artery Doppler PI & & & \\
Right & $1.38 \pm 0.41$ & $2.49 \pm 0.86$ & $<0.001$ \\
Left & $1.43 \pm 0.38$ & $2.48 \pm 0.93$ & $<0.001$ \\
Mean & $1.41 \pm 0.33$ & $2.48 \pm 0.87$ & $<0.001$ \\
\hline
\end{tabular}

Table 3: Pregnancy outcomes in the two groups.

\begin{tabular}{lccc}
\hline & Sildenafil Group & Placebo Group & $p$-value \\
\hline Clinical pregnancy & $186(43.7 \%)$ & $147(34.5 \%)$ & 0.006 \\
Multiple pregnancy & $13(3.05 \%)$ & $9(2.11 \%)$ & 0.38 \\
Ectopic pregnancy & $0(0 \%)$ & $1(0.23 \%)$ & 0.99 \\
\hline
\end{tabular}

Table 4: Risk analysis of pregnancy outcomes in the two groups.

\begin{tabular}{lccc}
\hline & Value & $95 \%$ CI & $p$-value \\
\hline Relative risk & 0.85 & $0.77-0.95$ & 0.006 \\
Number needed to treat (NNT) & 10.89 & $6.36-37.84$ & \\
\hline
\end{tabular}
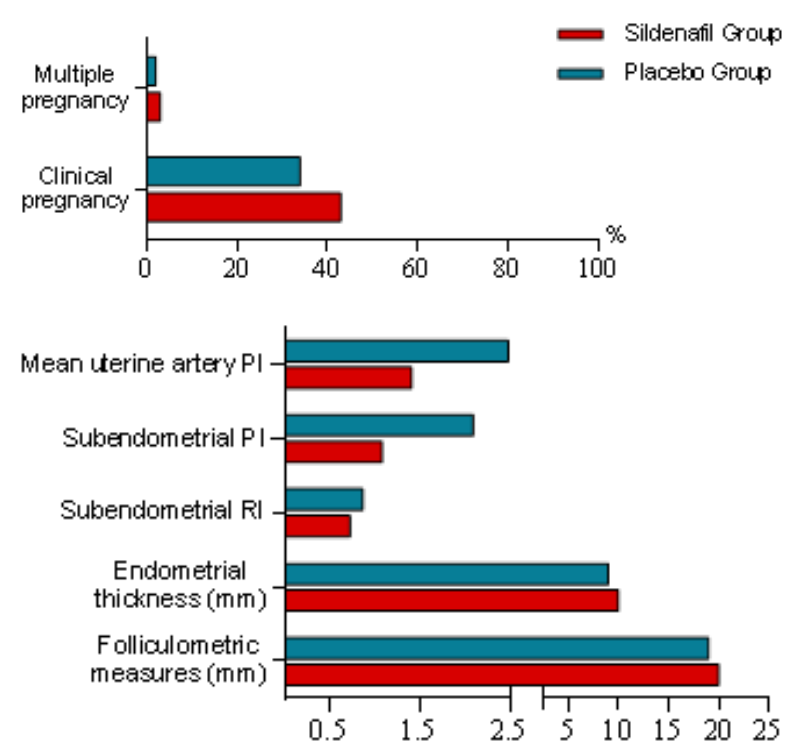

Fig. 2: Bar graph summarizing pregnancy outcomes (upper) and preovulatory ultrasonographic findings (lower) in the two groups.

\section{DISCUSSION}

Although clomiphene citrate successfully induces ovulation in $75-80 \%$ of PCOS patients, pregnancy is unfortunately achieved in only $34-40 \%$ of patients within 6 induction cycles ${ }^{[16]}$. This wide discrepancy is attributed to three main causes; anti-estrogenic effect of clomiphene citrate on cervical and endometrial function, clomipheneinduced increased LH secretion and the presence of another contributing factor for infertility ${ }^{[17]}$.

Clomiphene citrate is known to affect endometrial development and receptivity and actually the utlrasonographic finding of thin endometrium during clomiphene citrate treatment is not uncommon ${ }^{[18]}$. Actually, endometrial growth during the follicular phase (apart from 
being estrogen dependent) varies also with the endometrial and subendometrial vascularity regardless of the estradiol or progesterone concentrations ${ }^{[19]}$. Clomiphene citrate is known to affect both elements; besides acting as an antagonist at the endometrial estrogen receptor, diminished uterine and endometrial blood flow in clomiphene-induced cycles was reported in several studies. For instance, Palomba et al. ${ }^{[20]}$ demonstrated the increased resistance in the uterine, endometrial and subendometrial vasculatures in clomiphene-induced ovulatory cycles in PCOS women compared to healthy ovulatory women in accordance with several other studies ${ }^{[21-23]}$. In addition, clomiphene citrate is a highly potent prostaglandin synthesis inhibitor being comparable in this regard to indomethacin, thus raising concentrations of prostaglandin dehydrogenase in the endometrium ${ }^{[24]}$; which negatively affects the implantation process. This was evident in the study of Nakagawa et al. ${ }^{[25]}$ who found that pregnancy rates following fresh embryo transfer for ovarian stimulation cycles using clomiphene citrate were poor $(24.0 \%)$ even if hormonal treatment was given after clomiphene citrate treatment and endometrial thickness was recovered.

At least in theory, sildenafil citrate (a phosphodiesterase- 5 inhibitor with vasodilator effect) could be used to improve endometrial development in clomiphene-induced cycles. Sildenafil citrate was shown to have selective endometrial vasodilatory action in women with Asherman syndrome ${ }^{[26]}$ and improves endometrial development in women with thin endometrium by increasing radial artery flow ${ }^{[27]}$. In addition, animal studies showed that sildenafil citrate modulates endometrial receptivity by affecting endometrial VEGF and $\beta 3$ integrin expression during implantation window ${ }^{[28]}$. Moreover, sildenafil citrate was shown to have an immunomodulatory effect on the peri-implantation endometrial microenvironment by inhibiting NK-cell activity ${ }^{[29]}$.

Thus, although empirical, we postulated that sildenafil citrate adjuvant therapy in PCOS women failing to conceive despite ovulatory clomiphene-induced cycles might ameliorate not only clomiphene-related antiestrogenic endometrial effect, but also defects of endometrial receptivity and immunologic implantation and early pregnancy failure. This postulate, if proven correct, might evolve into a novel line of treatment for either failed induction of ovulation or even de novo induction of ovulation; rather than resorting to gonadotrophin induction of ovulation which is more expensive, requires close monitoring, carries higher risk of ovarian hyperstimulation syndrome and multiple pregnancy and, more importantly, might end with failure to conceive if another cause of infertility (e.g. endometrial receptivity defect) is involved.

According to our results, sildenafil citrate adjuvant therapy significantly increased clinical pregnancy rate, improved endometrial development in terms of endometrial thickness and pattern and uterine and subendometrial blood flow.
In concordance with our results, several studies demonstrated the efficacy of vaginal sildenafil in improving endometrial growth, endometrial blood flow and pregnancy rates in women with failed IVF/ICSI cycle associated with thin endometrium ${ }^{[7,30-32]}$. Few reports investigated the use of sildenafil vaginal suppositories as adjunct to clomiphene citrate induction of ovulation. Malinova et al. ${ }^{[12]}$ reported increased endometrial thickness and uterine blood flow when clomiphene is combined with $25 \mathrm{mg}$ of sildenafil vaginally as a first-line treatment for ovulation induction in PCOS. In the self-controlled clinical trial of Fetih et al. ${ }^{[13]}$, endometrial thickness and uterine blood flow significantly increased in 36 women with clomiphene failure and thin endometrium in their 7 th induction cycle using clomiphene citrate and supplemental sildenafil vaginal gel $(5 \mathrm{gm}$, containing 50mg sildenafil) twice daily starting day 8 of the cycle till HCG injection day. However, several points should be noted: firstly, the self-controlled design used in Fetih et al. study, although being the best to demonstrate the paired difference in endometrial thickness and uterine blood flow, could not assess the main clinical outcomes, e.g. clinical pregnancy rate, due to interference by the cumulative effect of repeated clomiphene cycles. Secondly, despite the fewer side effects, there is no registered vaginal dosage form for sildenafil and previous studies ${ }^{[7,31,32]}$ using prepared suppositories or gel from mashed and dissolved oral tablets obviously lacked pharmaceutical characterization of various pharmacokinetic parameters. Thus, we preferred using the rather pharmacokinetically consistent oral form.

In light of these results, we recommend that trial of adjuvant sildenafil citrate should be commenced at least in the setting of clomiphene failure before resorting to gonadotropin therapy.

The strengths of our study include its randomized placebo-controlled design and the evaluation of a clinical outcome, rather than radiologic findings as in previous studies. However, our study is limited by its proof of principle nature; so that we did not include women receiving gonadotropins (the routine line of treatment after clomiphene failure) and compare their outcome with combined extended clomiphene induction with sildenafil citrate.

\section{CONFLICT OF INTEREST}

There are no conflicts of interest.

\section{REFERENCES}

1. N.S. Weiss, S. Braam, T.E. König, M.L. Hendriks, C.J. Hamilton, J.M. Smeenk, C.A. Koks, E.M. Kaaijk, P.G. Hompes, C.B. Lambalk, F. Van Der Veen F, How long should we continue clomiphene citrate in anovulatory women? Hum. Reprod. 29 (11) (2014) 2482-2486. 
2. NICE, Fertility: Assessment and Treatment for People with Fertility Problems, Clinical Guideline 156, February 2013, www.nice.org.uk.

3. The Thessaloniki ESHRE/ASRM-Sponsored PCOS Consensus Workshop Group, Consensus on infertility treatment related to polycystic ovary syndrome, Hum. Reprod. 23 (2008) 462-477.

4. M.J. Eijkemans, B. Imani, A.G. Mulders, J.D. Habbema, B.C. Fauser, High singleton live birth rate following classical ovulation induction in normogonadotropic anovulatory infertility (WHO 2), Hum. Reprod.18 (2003) 2357-2362.

5. Y. Gonen, R.F. Casper, Sonographic determination of a possible adverse effect of clomiphene citrate on endometrial growth, Hum. Reprod. 5 (1990) 670-674.

6. E.G. Boyce, E.M. Umland, Sildenafil citrate: a therapeutic update, Clinical therapeutics 23 (1) (2001) 2-3.

7. G. Sher, J.D. Fisch, Effect of vaginal sildenafil on the outcome of in vitro fertilization (IVF) after multiple IVF failures attributed to poor endometrial development, Fertil. Steril.78 (5) (2002) 1073-1076.

8. G. Sher, C. Herbert, G. Maassarani, M.H. Jacobs, Assessment of the late proliferative phase endometrium by ultrasonography in patients undergoing in-vitro fertilization and embryo transfer (IVF/ET), Hum. Reprod. 6 (2) (1991) 232-237.

9. M. Jerzak, M. Kniotek, J. Mrozek, A. Górski, W. Baranowski, Sildenafil citrate decreased natural killer cell activity and enhanced chance of successful pregnancy in women with a history of recurrent miscarriage. Fertil. Steril. 90 (5) (2008) 1848-1853.

10. D. Villanueva-Garcia, D. Mota-Rojas, R. HernandezGonzalez, P. Sanchez-Aparicio, M.Alonso-Spilsbury, M.E. Trujillo-Ortega, R. Ramírez Necoechea, A.A. Nava-Ocampo, A systematic review of experimental and clinical studies of sildenafil citrate for intrauterine growth restriction and pre-term labour, J. Obstet. Gyn. 27 (3) (2007) 255-259.

11. P.C. Biyiksiz, S. Filiz, B. Vural, Is sildenafil citrate affect endometrial receptivity? An immunohistochemical study, Gynecol. Endocrinol. 27 (10) (2011) 767-774.

12. M. Malinova, T. Abouyta, M. Krasteva, The effect of vaginal sildenafil citrate on uterine blood flow and endometrium in the infertile women, Akush. Ginekol. (Sofiia) 52 (2013) 26-30.
13. A.N. Fetih, D.M. Habib, I.I. Abdelaal, M. Hussein, G.N. Fetih, E.R. Othman, Adding sildenafil vaginal gel to clomiphene citrate in infertile women with prior clomiphene citrate failure due to thin endometrium: a prospective self-controlled clinical trial, Facts Views Vis. Obgyn. 9 (1) (2017) 21.

14. Rotterdam ESHRE/ASRM-sponsored PCOS consensus workshop group. Revised 2003 consensus on diagnostic criteria and long-term health risks related to polycystic ovary syndrome (PCOS), Hum. Reprod. 19 (1) (2004) 41-47.

15. S.A. Amer, T.C. Li, M. Metwally, M. Emarh, W.L. Ledger, Randomized controlled trial comparing laparoscopic ovarian diathermy with clomiphene citrate as a first-line method of ovulation induction in women with polycystic ovary syndrome. Hum Reprod. 24 (1) (2008) 219-225.

16. R. Homburg, Clomiphene citrate - end of an era? A mini-review, Hum. Reprodu.20 (8) (2005) 2043-2051.

17. D. Hamilton-Fairley, S. Franks, 12 Common problems in induction of ovulation. Baillieres Best Pract Res Clin Obstet Gynaecol. 4 (3) (1990) 609-625.

18. M. Amita, T. Takahashi, S. Tsutsumi, T. Ohta, K. Takata, N. Henmi, S. Hara, H. Igarashi, K. Takahashi, H. Kurachi, Molecular mechanism of the inhibition of estradiol-induced endometrial epithelial cell proliferation by clomiphene citrate, Endocrinology 151 (1) (2010) 394-405.

19. N.J. Raine-Fenning, B.K. Campbell, N.R. Kendall, J.S. Clewes, I.R. Johnson, Endometrial and subendometrial perfusion are impaired in women with unexplained subfertility, Hum. Reprod. 19 (11) (2004) 2605-2614.

20. S. Palomba, T. Russo, F. Orio Jr, A. Falbo, F. Manguso, A. Sammartino, A. Tolino, A. Colao, E. Carmina, F. Zullo, Uterine effects of clomiphene citrate in women with polycystic ovary syndrome: a prospective controlled study, Hum. Reprod.;21 (11) (2006) 2823-2829.

21. C.C. Hsu, H.C. Kuo, S.T. Wang, K.E. Huang, Interference with uterine blood flow by clomiphene citrate in women with unexplained infertility, Obstet. Gynecology. 86 (6) (1995) 917-921.

22. I. Miwa, H. Tamura, A. Takasaki, Y. Yamagata, K. Shimamura, N. Sugino, Pathophysiologic features of "thin" endometrium. Fertil. Steril. 91 (4) (2009) 998-1004 
23. A. Nakai, A. Yokota, T. Koshino, T. Araki, Assessment of endometrial perfusion with Doppler ultrasound in spontaneous and stimulated menstrual cycles, J. Nippon Med. Sch. 69 (4) (2002) 328-332.

24. L.J. Lerner, P. Carminati, P. Schiatti, Correlation of anti-inflammatory activity with inhibition of prostaglandin synthesis activity of nonsteroidal antiestrogens and estrogens, Proc. Soc. Exp. Biol. Med. 148 (2) (1975) 329-332.

25. K. Nakagawa, M. Kaneyama, Y. Nishi, R. Sugiyama, H. Motoyama, R. Sugiyama, Clomiphene citrate affects the receptivity of the uterine endometrium, Reprod Med. Biol. 14 (2) (2015) 73-78.

26. M. Zinger, J.H. Liu, M.A. Thomas, Successful use of vaginal sildenafil citrate in two infertility patients with Asherman's syndrome, J. Womens Health (Larchmt) 15 (4) (2006) 442-444.

27. A. Takasaki, H. Tamura, I. Miwa, T. Taketani, K. Shimamura, N. Sugino, Endometrial growth and uterine blood flow: a pilot study for improving endometrial thickness in the patients with a thin endometrium, Fertil. Steril. 93 (6) (2010) 1851-1858.

28. P.C. Biyiksiz, S. Filiz, B. Vural, Is sildenafil citrate affect endometrial receptivity? An immunohistochemical study, Gynecol. Endocrinol.27 (10) (2011) 767-774.

29. M. Jerzak, M. Kniotek, J. Mrozek, A. Górski, W. Baranowski. Sildenafil citrate decreased natural killer cell activity and enhanced chance of successful pregnancy in women with a history of recurrent miscarriage, Fertil. Steril. 90 (5) (2008) 1848-1853.

30. G. Sher, J.D. Fisch, Vaginal sildenafil (Viagra): a preliminary report of a novel method to improve uterine artery blood flow and endometrial development in patients undergoing IVF, Hum. Reprod. 15 (4) (2000) 806-809.

31. K.S. Richter, K.R. Bugge, J.G. Bromer, M.J. Levy, Relationship between endometrial thickness and embryo implantation, based on 1,294 cycles of in vitro fertilization with transfer of two blastocyststage embryos, Fertil. Steril. 87 (1) (2007) 53-59.

32. A. Takasaki, H. Tamura, I. Miwa I, T. Taketani T, K. Shimamura, N. Sugino, Endometrial growth and uterine blood flow: a pilot study for improving endometrial thickness in the patients with a thin endometrium, Fertil. Steril. 93 (6) (2010) 1851-1858. 